\title{
Undergraduate nursing students' knowledge and attitude regarding pain management of children in Upper Egypt
}

\author{
Marzoka Abd El-Aziz Gadallah ${ }^{1}$, Atyat Mohammed Hassan *1, Soad Abd El-Hamied Shargawy ${ }^{2}$ \\ ${ }^{1}$ Pediatric Nursing Department, Faculty of Nursing, Assiut University, Egypt \\ ${ }^{2}$ Community Health Nursing Department, Faculty of Nursing, Assiut University, Egypt
}

Received: November 10, 2016

DOI: $10.5430 /$ jnep.v7n6p100
Accepted: December 18, $2016 \quad$ Online Published: February 7, 2017

URL: http://dx.doi.org/10.5430/jnep.v7n6p100

\begin{abstract}
Pain assessment and management require nurses to be equipped with adequate knowledge and proper attitudes. This research aimed to assess undergraduate nursing students' knowledge and attitude regarding pain management in children. Descriptive cross-sectional research design was utilized. This work was implemented at Faculty of Nursing in Assiut University. The study subjects consisted of convenient sample of undergraduate nursing students at third and fourth year during the academic year 2015-2016. One tool was used for this study consisted of two parts: part I: Demographic questionnaire, and part II: Pediatric Nurses' Knowledge and Attitudes Survey Regarding Pain (PNKAS). Fifty-six percent of undergraduate nursing students had unsatisfactory score regarding PNKAS. The highest percentage $76.2 \%$ of participating students had less than 50\% of total score of knowledge and attitude regarding pain especially to pharmacological information. The study concluded that nursing students had poor knowledge and attitude regarding pain management by using PNKAS especially in the part of pain assessment and pharmacological pain management. The more contact with pediatric patients the higher the knowledge and positive attitudes among undergraduate nursing students. The study recommended that the pediatric staff should review the curriculum to enrich more about assessment and management of pain.
\end{abstract}

Key Words: Undergraduate nursing student, Knowledge, Attitude, Pain management

\section{INTRODUCTION}

Pain is a major source of distress for children and their families as well as health care providers. Children may experience pain as a result of surgery, injuries, acute and chronic illnesses, and medical or surgical procedures. It can lead to serious physical and emotional consequences such as increased oxygen consumption and alterations in blood glucose metabolism. In addition, the experience of untreated pain early in life may lead to long term physiologic, psychological and behavioral consequences for the child. ${ }^{[1,2]}$ According to Mathews (2011), forty percent of children complain of acute pain while chronic pain affects at least $15 \%-20 \% .^{[3]}$

One of the important responsibilities of health care personnel is to relieve pain as possible. It is unethical to let the child suffer from pain without any trials to relieve pain or provide high-quality treatment. ${ }^{[4]}$ This comes in the same line with the American Pain Society (1995) ${ }^{[5]}$ which labeled the pain as "the fifth vital sign" to emphasize the importance of as-

\footnotetext{
* Correspondence: Atyat Mohammed Hassan; Email: atyathassan@aun.edu.eg; Address: Pediatric Nursing Department, Faculty of Nursing, Assiut University, Egypt.
} 
sessing pain frequently and providing appropriate treatment. The goal is to encourage health care professionals to assess pain every time and to institute measures to manage it. ${ }^{[6]}$

A research conducted by Chin Tracy (2007) ${ }^{[7]}$ to assess nursing students' knowledge and attitudes regarding pediatric pain at California State University, concluded that many complex and interrelated factors that have participated to the undertreatment of pediatric pain, including professionals' misconceptions about pain and its management; limited clinical information regarding pain control and analgesic usage; persistent myths discounting a child's ability to experience pain; the complexities of pain assessment in children, particularly nonverbal children; and the lack of awareness of the detrimental effects of unrelieved pain related to illness or medical care. Two of the most common misconceptions held by student nurses contributing to the undertreatment of pediatric pain are the fears related to depression and addiction from opioid treatments.

Children and their families have the right to receive pain management that is both timely and effective. The accurate assessment and effective management of a pediatric patient's pain is a vital nursing activity requiring a nurse who possess an accurate theoretical knowledge base of pain, its assessment, management and appropriate attitudes unmarred by myths. The assessment of nursing students' knowledge and attitudes may bring to light information that may assist in the development of appropriate strategies to address educational needs related to pediatric pain assessment and management. ${ }^{[7]}$ Some studies in Jordan have indicated that the student nurse has poor knowledge of pain and management skills among children. ${ }^{[8,9]}$ Although scientific knowledge about children's pain is increasing, the undertreatment of pediatric pain is still a serious problem. ${ }^{[10]}$ It can delay healing and may develop into chronic pain. ${ }^{[1]}$ Under-treated chronic pain can limit daily activities, increase disability, negatively affect the quality of life, create suffering, cause anxiety, depression, anger, and fear, and increase the risk for suicide. ${ }^{[12]}$

In a study implemented by Duke et al. (2013) ${ }^{[13]}$ on pain management knowledge and attitudes of baccalaureate nursing students from the University of Texas at Tyler College of Nursing \& Health Sciences, it was found that; nursing faculty is in a unique position to significantly address the problem of pain management through facilitating the acquisition and utilization of knowledge by the next generation of nurses who are now undergraduate nursing students. Studies also indicated that having faculty students who are knowledgeable about pain management was an important resource. Also, these studies applied for undergraduate nursing students by
Plaisance and Logan (2006) $)^{[14]}$ and Goodrich $(2006)^{[15]}$ who concluded that there are a large gaps in knowledge and misconceptions regarding opioids, addiction, dose of analgesic, difference between addiction, dependence and tolerance, and opioid side effects.

Nurses play an important role in assessing and managing children's pain during hospitalization. They spend most of their time at the patient's bedside as compared to other healthcare professionals; they perform an instrumental role in the assessment and evaluation of pain. Therefore, they must become the primary agents of change for better pain management outcomes within patient populations. ${ }^{[16]}$ Consequently, if student nurses are insufficiently educated and ill prepared to effectively relieve pain, the patient ultimately suffers. For this reason, undergraduate nursing students must be well educated and knowledgeable about pain and its management to improve patient outcomes and collaborate efficiently with other healthcare professionals to successfully manage pain.

\subsection{Significance of study}

Undergraduate nursing students' knowledge and attitudes toward pain management in children affect nursing care. ${ }^{[16]}$ Hence, implementing these roles necessitate that nursing students achieve a comprehensive solid knowledge of pain and its management in the undergraduate nursing program. Also, how to transfer these behaviors learned from pain management education into the clinical setting. ${ }^{[14]}$ If student nurses have poor knowledge and inadequate training to assess and mange pain, the patient ultimately suffers. In addition, many studies conducted to assess and apply different types of pain management actually on pediatric patients. On the other hand no studies were conducted to assess knowledge and attitude of undergraduate nursing students on pain management skills in Egypt.

\subsection{Aim of the study}

This study aimed to assess undergraduate nursing students' knowledge and attitudes regarding pain management in children.

\subsection{Research questions}

(1) What are the current knowledge and attitudes regarding pain management among undergraduate nursing students?

(2) Are there relationships between demographic characteristics of undergraduate nursing students and their knowledge and attitudes regarding pain management? 


\section{SubJECTS AND METHOD}

\subsection{Design}

Descriptive cross-sectional research design was utilized.

\subsection{Setting}

This work was implemented at Faculty of Nursing in Assiut University in Upper Egypt. It is a governmental educational institution. It was established in 1982, offers Bachelor degree in nursing science. The study period is five years; four of these are academic study at the faculty and the last fifth year is clinical training year under the faculty staff supervision. English is the language of teaching and learning for the students in this institution.

\subsection{Study participants}

A convenient sample of third and fourth year nursing students who had studied pediatric nursing curriculum in the second semester of the academic year 2015-2016 were enrolled. The researchers distributed 510 questionnaires, 22 of them didn't return the questionnaires and 17 returned incomplete questionnaires which were excluded, the total sample was 471 .

\subsection{Sample size}

It was calculated by (Epi-Info 6.04d) with a 95\% confidence level using the sample size equation for estimation of single proportion. The optional sample size was 375 . The actual sample increased to 471 students to compensate any dropout.

\subsection{Tools of data collection}

One tool was used for this study which included two parts:

Part I: Demographic questionnaire which included: age, gender, residence, academic year, last qualifications before entering the faculty, highest degree attained in nursing in the last year, work in private setting, and attending any pain management courses, seminars or lectures.

Part II: Pediatric Nurses' Knowledge and Attitudes Survey Regarding Pain (PNKAS), it consisted of 42-item inventory developed by Manworren (2000) ${ }^{[17]}$ as a modification of McCaffery and Ferrell's (1997) ${ }^{[18]}$ for use with pediatric nurses. It is a self-administered survey assessing nurses' knowledge and attitudes regarding pain management. It included pain assessment and the use of analgesics and non-pharmacologic interventions for pain in the pediatric population. The survey includes 25 true or false questions, 13 multiple choice questions, and two-part case study questions. The PNKAS was selected for use in the study after thorough review of literature on knowledge and attitudes toward pain and pain management in the pediatric population by many researchers as: Chin Tracy (2006), ${ }^{[7]}$ Chiang et al. (2006), ${ }^{[16]}$ Ortiz 102 et al. (2015) ${ }^{[19]}$ and Laprise (2016). ${ }^{[20]}$ Also, Duke et al. (2013), ${ }^{[13]}$ Al-Khawaldeh et al. (2013) ${ }^{[9]}$ and Al Omari $(2016)^{[8]}$ who have found it a suitable tool for use with undergraduate nursing students because it was reliable. Test re-test reliability ( $r=0.67)$, Cronbach's alpha was 0.75 and valid.

\subsection{Procedure}

Research proposal was approved by Ethical Committee in the Faculty of Nursing. An official permission to collect data was obtained from the Dean of Faculty of Nursing, Assiut University. Written consent was obtained from students who were willing to participate in the study, after explaining nature and aim of the study. A pilot study was carried out on $(10 \%)$ of nursing students who were excluded from the sample. It was conducted to assess clarity of the tool and time needed to fulfill the tool. As the result of the pilot study, there was no modification needed.

The researcher collected data in the first semester of the academic year 2015-2016, for fourth year students and in the end of second semester for third year students after finishing the pediatric course, the student took about 25-35 minutes to fill the questionnaire. The researchers used the questionnaire in its English version as it was the students' language of study at faculty of nursing. The scoring system of nursing students' PNKAS; the correctly answered question was scored 1 point, and the incorrect zero point. The total score of this knowledge was converted into a percent score. A student who attained $50 \%$ of the total score was considered having satisfactory knowledge, while a score of less than $50 \%$ was considered unsatisfactory. ${ }^{[14]}$

\subsection{Statistical analysis}

Data entry was done using SPSS version 16.0 statistical software package. It was presented using descriptive statistics as Mean and standard deviation, frequencies and percentages variables were compared using chi-square test. Statistical significance was considered at $p$-value $<.05$.

\section{Results}

Table 1 showed that more than half $(57.1 \%)$ of students, their age ranged from 22-23 years and the majority (93.4\%) of them were females. More than two-thirds (69.6\%) of students lived in rural area and only (11.9\%) of them worked in private hospital during summer holiday and more than half of students $(56.3 \%)$ didn't attend any pain management courses, seminars or lectures.

ISSN 1925-4040 E-ISSN 1925-4059 
Table 1. Characteristics of undergraduate nursing students

\begin{tabular}{|c|c|}
\hline Items & $\mathbf{N}(\%)$ \\
\hline \multicolumn{2}{|l|}{ Age/Years } \\
\hline $21-\downarrow 22$ & $202(42.9)$ \\
\hline $22-23$ & $269(57.1)$ \\
\hline Total & $471(100)$ \\
\hline Mean \pm SD & $21.73 \pm 0.73$ \\
\hline \multicolumn{2}{|l|}{ Gender } \\
\hline Male & $31(6.6)$ \\
\hline Female & $440(93.4)$ \\
\hline Total & $471(100)$ \\
\hline \multicolumn{2}{|l|}{ Residence } \\
\hline Rural & $328(69.6)$ \\
\hline Urban & $143(30.4)$ \\
\hline Total & $471(100)$ \\
\hline \multicolumn{2}{|l|}{ Academic year } \\
\hline Third & $183(38.8)$ \\
\hline Fourth & $288(61.2)$ \\
\hline Total & $471(100)$ \\
\hline \multicolumn{2}{|c|}{ Last qualifications before entering the faculty } \\
\hline General Secondary School & $325(69)$ \\
\hline Technical Institute of Health or Nursing & $146(31)$ \\
\hline Total & $471(100)$ \\
\hline \multicolumn{2}{|c|}{ Highest degree attained in nursing in the last year } \\
\hline Pass & $10(2.1)$ \\
\hline Good & $116(24.6)$ \\
\hline Very good & $232(49.2)$ \\
\hline Excellent & $113(24.1)$ \\
\hline Total & $471(100)$ \\
\hline \multicolumn{2}{|c|}{ Working in private hospital during summer holiday } \\
\hline Yes & $56(11.9)$ \\
\hline No & $415(88.1)$ \\
\hline Total & $471(100)$ \\
\hline \multicolumn{2}{|c|}{ Attending courses, seminars or lecture about pain } \\
\hline Yes & $206(43.7)$ \\
\hline No & $265(56.3)$ \\
\hline Total & $471(100)$ \\
\hline
\end{tabular}

Table 2 illustrated that the highest percentage of the correct answers was awarded for question number (22) with a percent of $(76.8 \%)$ followed by question number (8) with a percent of $70.9 \%$.

Table 3 indicated that the highest percentage of the incorrect answers as regard pharmacological information questions number $(38,26,31,39 \mathrm{~b})$ and pain assessment questions number $(37,39 \mathrm{~A}, 1,35)$.

Table 4 represented that there was no statistically significant differences between all items of students' characteristics and

Published by Sciedu Press their total score of PNKAS except for those who were working at private hospital during summer holiday with $p=.002$.

Figure 1 showed that more than half of the studied sample (56\%) was having unsatisfactory knowledge level.

Figure 2 revealed that the highest percentage $76.2 \%$ of the undergraduate nursing students answered less than $50 \%$ of total items of PNKAS correctly.

\section{Discussion}

Pain is the first complaint of any medical or surgical problems of infant or child. Therefore, it is one of the important duties of health care professionals to relieve pain and suffering as possible. Relieving children's pain has been perceived as a vital public health issue that needs immediate global attention since failing to manage pain can lead to economic and human burden on patients, their families, and society. ${ }^{[21,22]}$

This study aimed to assess undergraduate nursing students' knowledge and attitude as regard pain management in children. The results revealed that more than half of nursing students' knowledge and attitudes about pain management was unsatisfactory as shown in Figure 1 and more than threequarters of undergraduate nursing students, their score response to PNKAS questions were less than $50 \%$ as shown in Figure 2. These results were in agreement with $\mathrm{Al}$ Omari Omar (2016) ${ }^{[8]}$ and Al-Khawaldeh et al. (2013) $)^{[9]}$ who stated that nursing students' knowledge of and attitudes toward pain in Jordan is far from optimal. And also, the same findings were obtained from previous studies of Latchman Jessica (2010), ${ }^{[23]}$ Chiu et al. (2003), ${ }^{[24]}$ Rhimi-Madiseh et al. (2010), ${ }^{[25]}$ Lunsford (2014), ${ }^{[26]}$ Chow and Chan $(2015)^{[27]}$ and Plaisance and Logan (2006). ${ }^{[14]}$

Many factors contributed to nursing students' poor knowledge and attitudes toward pain management. First, pediatric nursing course in Assiut University, faculty of nursing lacked pediatric pain management theoretically and how to manage it effectively in clinical practice. Second, students spend short time in clinical field with their patients and therefore they have limited opportunity to assess or manage pain due to increase number of students compared to staff.

Hemsirelik Ulusal Çekirdek Egitim Program (HUCEP) $(2003)^{[28]}$ added that there was no standards for the duration and content of pain management courses. The "National Core Curriculum Program for Nursing Education Standardization Commission" has made "pain management" an "essential" part of the nursing curriculum. However Lai et al. $(2003)^{[29]}$ stated that the trainers need to be experts in pain management and the training subjects should be of adequate duration with content that is appropriate for the pain management applications encountered in the unit. 
Table 2. Frequency and percentages distribution of top ten correct answers of undergraduate nursing students

\begin{tabular}{|c|c|c|c|}
\hline $\begin{array}{l}\text { Question } \\
\text { Number }\end{array}$ & Items & Key answer & $\begin{array}{l}\text { Students' } \\
\text { answers (\%) }\end{array}$ \\
\hline 22 & $\begin{array}{l}\text { Subsequent doses of opioid analgesics adjusted according to the child's individual } \\
\text { response after first dose. }\end{array}$ & True & $362(76.8)$ \\
\hline 8 & $\begin{array}{l}\text { Giving maximum treatment of pain in the first procedure for children with } \\
\text { repeated painful procedure. }\end{array}$ & True & $334(70.9)$ \\
\hline 20 & Religious beliefs of a child about pain and suffering are necessary. & True & $305(64.7)$ \\
\hline 14 & Presence of parents isn’t necessary during painful procedures. & False & 301 (63.9) \\
\hline 5 & Similar stimuli give the same intensity of pain. & False & $299(63.5)$ \\
\hline 10 & Effect of oral acetaminophen $650 \mathrm{mg}$ is nearly equal to oral codeine $32 \mathrm{mg}$. & True & $293(62.2)$ \\
\hline 6 & $\begin{array}{l}\text { Severe pain is not affected by Ibuprofen and other non-steroidal anti-inflammatory } \\
\text { agents. }\end{array}$ & False & $285(60.5)$ \\
\hline 9 & $\begin{array}{l}\text { Children who have been using opioid analgesic more than one month rarely having } \\
\text { respiratory depression. }\end{array}$ & True & $260(55.2)$ \\
\hline 34 & Choose which of these drugs are effective for the treatment of severe pain? & $\begin{array}{l}\text { All of the } \\
\text { above }\end{array}$ & $251(53.3)$ \\
\hline 3 & Distraction of children has negative effects on severe pain. & False & $247(52.4)$ \\
\hline
\end{tabular}

Table 3. Frequency and percentages distribution of top ten incorrect answers of undergraduate nursing students

\begin{tabular}{|c|c|c|c|}
\hline $\begin{array}{l}\text { Question } \\
\text { Number }\end{array}$ & Items & Key answer & $\begin{array}{l}\text { Students' } \\
\text { answers (\%) }\end{array}$ \\
\hline 38 & Definition of narcotic/opioid addiction. & $<1 \%$ & $453(96.2)$ \\
\hline 26 & $\begin{array}{l}\text { The recommended route of administration of opioid analgesics to children } \\
\text { with prolonged sever pain is: }\end{array}$ & Oral & $442(93.8)$ \\
\hline 37 & What about the percentage of the child can report pain. & $0-10$ & $438(93.1)$ \\
\hline $39 \mathrm{~A}$ & $\begin{array}{l}\text { Marking on your record about his pain regarding your assessment of } \\
\text { Andrew’s pain. }\end{array}$ & 8 & $420(89.1)$ \\
\hline 1 & Severe pain must be changing vital signs & False & $411(87.3)$ \\
\hline 31 & $\begin{array}{l}\text { The probability of the child developing clinically significant respiratory } \\
\text { depression is: }\end{array}$ & $<1 \%$ & 408 (86.6) \\
\hline 35 & The person who can evaluate the severity of child's pain accurately is. & The child & 398 (84.5) \\
\hline 7 & $\begin{array}{l}\text { Non-pharmacological pain management is effective in mild and moderate } \\
\text { pain while rarely useful in severe pain. }\end{array}$ & False & $393(83.4)$ \\
\hline 39B & $\begin{array}{l}\text { According to the child's condition the pediatrician ordered "morphine IV 1-3 } \\
\text { mg q1h PRN pain relief.” which action you will take at this time: }\end{array}$ & $\begin{array}{l}\text { Giving morphine } \\
3 \text { mg IV now. }\end{array}$ & 381 (80.9) \\
\hline 11 & $\begin{array}{l}\text { Regarding to World Health Organization pain ladder recommendations } \\
\text { administering single analgesic agents rather than combining classes of drugs. }\end{array}$ & False & $372(79.00)$ \\
\hline
\end{tabular}

The first two items in the questionnaire were answered correctly by the majority of students "Subsequent doses of opioid analgesics adjusted according to the child's individual response after first dose". And "Giving maximum treatment of pain in the first procedure for children with repeated painful procedure". As represented in Table 2, these may be explained by the simplicity of these questions which can be easily expected by the students.

The second two items answered correctly by the majority of students were "Presence of parents isn't necessary during painful procedures". And "Religious beliefs of a child about pain and suffering". These findings can be explained in the light of the studied pediatric nursing curriculum which focused on the importance of parents' presence during hospitalization of children. In addition, these items assessed attitudes, which rarely taught, but they are often adopted from supervisors. These results were supported by Stanley \& Pollard (2013), ${ }^{[30]}$ Ortiz et al. (2015) ${ }^{[19]}$ and Al Omari Omar (2016). ${ }^{[8]}$

The present study also showed that nursing students had poor knowledge and negative attitudes in the areas of pain assessment and pharmacological pain management, side effects and 
when time addiction of opioid can occur as shown in Table 3, when addiction can occur. In addition, Chow and Chan which obstructs ability of the student nurses for performing pain assessment and management options for their pediatric patients. This result agreed with Chiang et al. (2006) ${ }^{[16]}$ who stated items related to knowledge of pharmacological treatment were the questions most frequently answered incorrectly by participants. A recent Jordanian study by Al Omari Omar $(2016)^{[8]}$ found similar results when most undergraduate Jordanian nursing students answered questions related to pain assessment, pharmacological pain management and (2010) ${ }^{[27]}$ and Plaisance and Logan $(2014)^{[14]}$ stated that the items with the poorest responses were related to medications actions, side effects and administration. Also, Chiang et al. (2006) ${ }^{[16]}$ found that pharmacological management did not increase after the educational program. Moreover, they have shown that student nurses have a particularly poor understanding of basic pharmacokinetic principles and analgesic agents.

Table 4. Relation between students' characteristics and their total score

\begin{tabular}{|c|c|c|c|c|c|c|c|}
\hline \multirow{3}{*}{ Students' Characteristics } & \multirow{3}{*}{$\begin{array}{l}\text { Total } \\
\text { Number }\end{array}$} & \multicolumn{4}{|c|}{ Total Score } & \multirow{3}{*}{$\chi^{2}$} & \multirow{3}{*}{$p$-value } \\
\hline & & \multicolumn{2}{|c|}{ Satisfactory level } & \multicolumn{2}{|c|}{ Unsatisfactory level } & & \\
\hline & & $\mathbf{N}$ & $\%$ & $\mathbf{N}$ & $\%$ & & \\
\hline \multicolumn{8}{|l|}{ Age (years) } \\
\hline $21-\downarrow 22$ & 202 & 86 & 42.6 & 116 & 57.4 & 0.283 & .595 \\
\hline $22-23$ & 269 & 121 & 45.00 & 148 & 55.00 & & \\
\hline \multicolumn{8}{|l|}{ Residence } \\
\hline Rural & 328 & 147 & 44.8 & 181 & 55.2 & 0.568 & .451 \\
\hline Urban & 143 & 60 & 41.9 & 83 & 58.1 & & \\
\hline \multicolumn{8}{|l|}{ Academic year } \\
\hline Third & 182 & 78 & 42.8 & 104 & 57.2 & 0.155 & .694 \\
\hline Fourth & 289 & 129 & 44.6 & 160 & 45.4 & & \\
\hline \multicolumn{8}{|c|}{ Last qualifications before entering the faculty } \\
\hline General Secondary School & 325 & 142 & 43.7 & 183 & 56.3 & 0.12 & .913 \\
\hline Technical Institute of Health or Nursing & 146 & 65 & 44.5 & 81 & 55.5 & & \\
\hline \multicolumn{8}{|c|}{ Highest degree attained in nursing in the last year } \\
\hline Pass & 10 & 4 & 40.0 & 6 & 60.0 & & \\
\hline Good & 116 & 52 & 44.8 & 64 & 55.2 & 4.465 & .198 \\
\hline Very good & 232 & 101 & 43.5 & 131 & 56.5 & & \\
\hline Excellent & 113 & 48 & 42.5 & 65 & 57.5 & & \\
\hline \multicolumn{8}{|c|}{ Working in private hospital during summer holiday } \\
\hline Yes & 56 & 33 & 60.00 & 23 & 40.00 & 9.337 & .002 \\
\hline No & 415 & 174 & 41.9 & 241 & 58.1 & & \\
\hline \multicolumn{8}{|c|}{ Attending courses, seminars or lecture about pain } \\
\hline Yes & 206 & 95 & 46.1 & 111 & 53.9 & 0.861 & .354 \\
\hline No & 265 & 112 & 42.3 & 153 & 57.7 & & \\
\hline
\end{tabular}

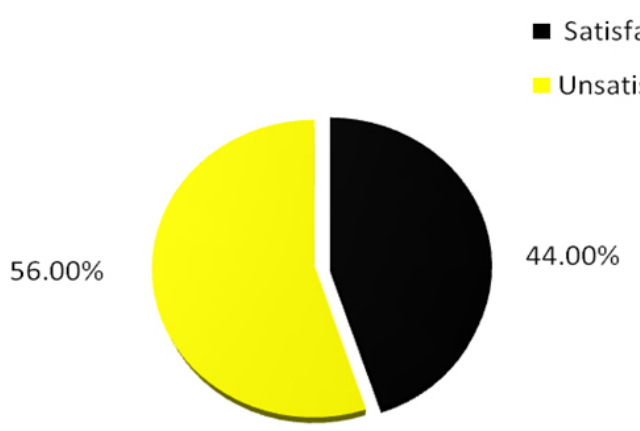

Figure 1. Percentage distribution of total score of undergraduate nursing students

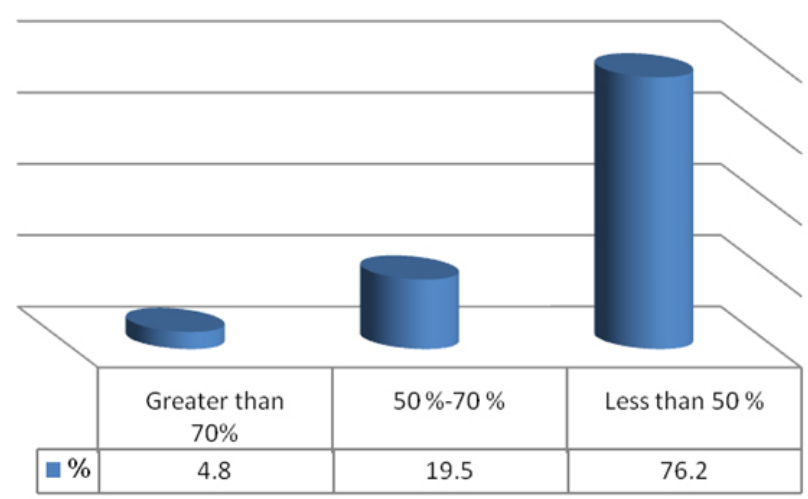

Figure 2. Percentage of undergraduate nursing students who answered items of the PNKAS correctly 
These findings can be clarified in the light of the fact that student nurses generally were weak on pharmacological knowledge. Furthermore, they have studied pharmacology in the first year 2 hours/week with no practical hours to strengthen the basic studied knowledge and when they reached the third year, most of the information gained may be lost and they didn't remember it. It is worth mentioning that pain assessment or using pain scales not familiar to the student nurses in the pediatric nursing curriculum. Furthermore, method of teaching during practical lessons in the pediatric nursing labs wasn't prepared to simulate the real setting of the pediatric hospital as regard pain assessment and management.

An additional cause for the low scores in pain assessment knowledge in our study was the policy of Assiut University Children Hospital which didn't permit the undergraduate nursing students to administer medications so there was no experience regarding treatment or method of administration and doses of medications. The experience is limited to observations during clinical practice; this explanation was supported by Kaki (2008), ${ }^{[31]}$ Oritz et al. 2015 ${ }^{[19]}$ and Al OMari (2016). ${ }^{[8]}$

Concerning the relation between students' characteristics and undergraduate PNKAS total score, there was a statistically significant difference as regard students working in private hospitals during summer holiday as presented in Table 4. This result was in agreement with Stanley and pollard $(2013)^{[30]}$ who indicated that there was a positive relationship between the level of knowledge and work experience. Pediatric nursing experience correlated significantly with higher knowledge levels. Meanwhile this result disagreed with Duke et al. (2008) ${ }^{[13]}$ and Rahimi-Mediseh et al. (2010) ${ }^{[25]}$ who found that no significant difference was found between nursing students who had work experience related knowledge and attitude survey regarding pain (KASRP) scores.
This may explain that, students who work in private hospitals during the summer holiday took the responsibility to patient care and the patients had the right to complain if any shortening occurred. So, students are encouraged to deal with many patients, assessed their pain and learn how to manage it.

\section{Conclusion}

Nursing students had poor knowledge and attitudes as regard pain management when using PNKAS especially in the part of pain assessment and pharmacological pain management. Undergraduate student nurses who work in private hospitals during summer holiday had better knowledge and attitudes compared to others. More than three quarters of undergraduate nursing students answered less than fifty percent of total items correctly.

\section{RECOMMENDATIONS}

(1) The pediatric nursing staff should review the curriculum and enrich it more about pain assessment and management.

(2) Preparing pediatric nursing labs with sufficient facilities to strengthen skills regarding pain assessment and management.

(3) Interventional studies for preparing new graduate nursing students with theoretical knowledge about pain, and its management in clinical practice with emphasis on pharmacological and non-pharmacological interventions.

(4) Teaching pharmacology course for nursing students of the second year instead of the first year.

\section{Conflicts of InTERest Disclosure}

The authors declare that there is no conflict of interest.

\section{REFERENCES}

[1] Hockenberry J, Kathy C, Olga T, et al. Managing Painful Procedures in Children with Cancer. Pediatric Hematology/Oncology Journal. 2011; 33 (2): 119-27. PMid:21285907 https ://doi .org/10.109 7/MPH. Ob013e3181f46a65

[2] Bowden VR, Greenberg CS. Pediatric Nursing Procedures. 2nd ed., Lippincott Williams \& Wilkins, Philadelphia. 2008.

[3] Mathews Lulu. Pain in Children: Neglected, Unaddressed and Mismanaged. Indian J Palliat Care. Jan 2011; 17(Suppl): S70-S73.

[4] Gunningberg L, Idvall E. The quality of postoperative pain management from the perspective of patients, nurses, and patients' records. Journal of Nursing Management. 2007; 15: 756-766. PMid:17897153 https://doi.org/10.1111/j.1365-2934.2006.00753.x

[5] American Pain Society. Quality improvement guidelines for the treat- ment of acute pain and cancer pain. JAMA. 1995 Dec 20; 274(23): 1874-80. PMid:7500539 https ://doi.org/10.1001/jama. 199 5.03530230060032

[6] Kyle T, Carman S. Essentials of Pediatric Nursing. Pain management in children. 2nd ed., Lippincott Williams \& Wilkins, Philadelphia. 2013. 405-9, 413, 421-22

[7] Chin Tracy. Nursing Students' Knowledge and Attitudes Regarding Pediatric Pain. Unpublished Master degree of Science in Nursing Dissertation in the College of Health and Human Services. California State University, 2007.

[8] Omar AO. Knowledge and attitudes of Jordanian nursing students toward children's pain assessment and management: A cross-sectional study. Journal of Nursing Education and Practice. 2016; 6(3): 51-58 http://dx.doi.org/10.5430/jnep.v6n3p51 
[9] Al-Khawaldeh OA, Al-Hussami M, Darawad M. Knowledge and attitudes regarding pain management among Jordanian nursing students. Nurse Education Today. 2013; 33(4): 339-345. PMid:23398912 http://dx.doi.org/10.1016/j.nedt.2013.01.006

[10] Barakat-Johnson M, Mott S. Pain education package for rehabilitation nurses: a promising outcome. Journal of the Australasian Rehabilitation Nurses Association. 2016; 5: 18-26.

[11] D'Arcy YM. Pain Management: Evidence-Based Tools and Techniques for Nursing Professionals. Tucson, AZ: Lawyers and Judges Publishing Company. 2007.

[12] Berry PH, Covington E, Dahl J, et al. Pain: Current Understanding of Assessment, Management, and Treatments. Reston, Va: National Pharmaceutical Council, Inc and the Joint Commission on Accreditation of Healthcare Organizations. 2006.

[13] Gloria D, Barbara H, Susan Y, et al. Pain management knowledge and attitudes of baccalaureate nursing students and faculty. University of Texas at Tyler College of Nursing \& Health Sciences. Tyler, Texas Pain Management Nursing. 2013; 14(1): 11-19. http://dx.doi.org/10.1016/j.pmn.2010.03.006

[14] Plaisance L, Logan C. Nursing Students' Knowledge and Attitudes Regarding Pain. Pain Management Nursing. 2006; 7(4): 167175. PMid:17145491 http://dx.doi .org/10.1016/j.pmn. 200 6.09 .003

[15] Goodrich C. Students' and faculty members' knowledge and attitudes regarding pain management: A descriptive survey. Journal of Nursing Education. 2006; 45: 140-142. PMid:16562805

[16] Chiang LC. Student Nurses' Knowledge, Attitudes, and Self-Efficacy of Children's Pain Management: Evaluation of an Education Program in Taiwan. Journal of Pain and Symptom Management. 2007; 32(1): 82-89. PMid:16824988 https://doi .org/10.1016/j.jp ainsymman . 2006.01.011

[17] Manworren RC, Hayes JS. Pediatric nurses' knowledge and attitudes survey regarding pain. Pediatr Nurs. 2000; 26: 610-614. PMid:12026363

[18] McCaffery M, Ferrell BR. Nurses' knowledge of pain assessment and management: how much progress have we made? J Pain Symptom Manage. 2000; 14: 175-188. https://doi.org/10.1016/S088 5-3924 (97) 00170-X

[19] Ortiz I, Mario Ponce-Monter A, Héctor Rangel-Flores Eduardo, et al. Romo-Hernández Georginaand Escamilla-Acosta A Marco Nurses' and Nursing Students' Knowledge and Attitudes regarding Pediatric Pain. Hindawi Publishing Corporation Nursing Research and Practice. 2015. http://dx.doi.org/10.1155/2015/210860
[20] Jessica L. Identification of student nurses' knowledge and attitude regarding pediatric pain management. University of Connecticut, School of Nursing. 2016. Available from: http://digitalcommo ns. uconn.edu/usp_projects/28

[21] Finley GA. Why children's pain matters. International Association for the Study of Pain. Pain Clinical Updates. 2005; 13(4): 1-6.

[22] Ung A. Assessing knowledge, perceptions and attitudes to pain management among medical and nursing students: A review of the literature. British Journal of Pain. 2005.

[23] Latchman Jessica. Evaluating knowledge and attitude of undergraduate nursing students regarding pain management. Unpublished Master degree of science in nursing dissertation in the collage of nursing. University of south Florida. 2010.

[24] Chiu LH, Trinca J, Lim LM, et al. A study to evaluate the pain knowledge of two sub-populations of final year nursing students: Australia and Philippines. Journal of Advanced Nursing. 2003; 41(1): 99-108. PMid:12519293 https://doi.org/10.1046/j.1365-2648.20 $03.02511 . x$

[25] Rahimi-Madiseh M, Tavakol M, Dennick R. A quantitative study of Iranian nursing students' knowledge and attitudes towards pain: Implication for education. International Journal of Nursing Practice. 2010; 16(5): 478-483. PMid:20854345 http://dx.doi.org/10. $1111 / \mathrm{j} .1440-172 \mathrm{X} .2010 .01872 . \mathrm{x}$

[26] Lunsford L. Knowledge and Attitudes Regarding Pediatric Pain in Mongolian Nurses. Pain Management Nursing. 2014.

[27] Chow KM, Chan CY. Pain knowledge and attitudes of nursing students: A literature review. Nurse Education Today. 2015; 35: 366-372. PMid:25466789 https://doi.org/10.1016/j.nedt.2014.10 .019

[28] HUÇEP (Report Hemşirelik Ulusal Çekirdek Eğitim Program). (National Core Curriculum Program for Nursing Education). GATA Basımevi, Ankara Türkiye. 2003: 1-36.

[29] Lai YH, Chen ML, Tsai LY, et al. Are nurses prepared to manage cancer pain? A national survey of nurses' knowledge about pain control in Taiwan. Journal of Pain and Symptom Management. 2003; 26(5): 1016-1025. https://doi.org/10.1016/S0885-3924(03 )00330-0

[30] Stanley M, Pollard D. Relationship between knowledge, attitudes, and self-efficacy of nurses in the management of pediatric pain. Pediatric Nursing. 2013; 39(4): 165-171. PMid:24027950

[31] Kaki AM. Pain status in Saudi governmental hospital. Saudi Med J. 2008; 29(3): 468-469. PMid:18327386 